Revista de Investigación Educativa 25

julio-diciembre, 2017 | ISSN 1870-5308 | Xalapa, Veracruz

Instituto de Investigaciones en Educación | Universidad Veracruzana

\title{
Ideologías en traducción. Literatura, didáctica, cultura
}

\author{
Dra. Cristina V. Kleinert \\ Docente \\ Universidad Veracruzana, México/University of Antwerp, Bélgica \\ ckleinert@uv.mx
}

Kasperska, I., Villegas, I., \& Donés, A. (Eds.) (2016). Ideologías en traducción. Literatura, didáctica, cultura. Fráncfort del Meno: Peter Lang GmbH. 284 páginas. ISBN 978-3-631-66746-o.

$\mathrm{C}$ uando nos acercamos a un libro queremos saber quiénes son los autores y, en líneas generales, qué nos deparará la lectura del mismo. Este libro fue concebido como producto del proyecto "Implicaciones ideológicas de la traducción intercultural (IDEO-TRANS)", propuesto y liderado por la Dra. Iwona Kasperska de la Universidad Adam Mickiewicz de Poznań, Polonia. Se trata de una propuesta de investigación científica, colaboración, reflexión e impulso de aprendizajes en torno a la relación entre las ideologías y la disciplina de la traducción, pero desde un abordaje amplio, creativo e incluyente. Participaron principalmente dos universidades públicas que albergan a dos de las editoras: la Universidad Adam Mickiewicz de Poznań, Polonia, y la Universidad Veracruzana campus Xalapa, México. Desde esa conformación, la riqueza de enfoques y visiones es sello de la publicación. De esta manera, la actual reseña se convierte en una invitación para acercarse y disfrutar de Ideologías en traducción, que será de utilidad para investigadores, académicos, estudiantes e incluso público en general interesado por el peso de las ideologías en procesos traductivos, traductológicos y culturales. 
Cada capítulo está situado temporal y espacialmente, y desde ahí los autores reflexionan sobre el mundo profesional de la traducción, las implicaciones de las elecciones traductológicas, los cánones literarios o las influencias entre autores literarios que escriben en idiomas que, para poder trascender en otras latitudes, son traducidos. Nos puede seducir y llevarnos a autores y corrientes o métodos de análisis de diversas disciplinas que alimentan y se nutren de la disciplina traductora o traslatoria. El libro cuenta con dieciséis miradas y muchas voces que nos conducen a lugares tan distantes como Cataluña, Polonia, México, Inglaterra o la Isla de Pascua, y a tiempos tan diversos como el siglo XVI, XVII, XVIII o los tiempos actuales, haciendo referencia a idiomas como castellano, catalán, polaco, náhuatl, inglés o francés, entre otros. Las combinaciones son sugerentes y abren rutas hacia exploraciones quizá insospechadas.

Participan trece autoras y tres autores, quienes se fijan en aspectos relacionados con la traducción y la ideología desde sus prácticas investigadoras, y en varios casos desde el campo educativo. Cada uno guía al lector por el complejo mundo de los traductores e intérpretes, quienes salen de sus invisibilidades, toman un papel activo, visible, con intención e influenciando por lo tanto los eventos comunicativos escritos $\mathrm{u}$ orales en los cuales intervienen. De hecho, queda claro a lo largo del libro que la práctica e intervención de cada traductor deja un sello, una huella con implicaciones que a la distancia afecta la recepción, la concepción o el entendimiento de obras estudiadas o leídas por un público que, al no poder acceder a la obra original, confía en las versiones traducidas del texto. Es gracias a este tipo de libros que se hace más evidente el papel que desempeñan los traductores e intérpretes como agentes con poder de decisión, con capacidad de intervención.

El hilo conductor del libro de 284 páginas está tejido por el afán de mostrarnos que la traducción (ya sea escrita u oral) no está libre de ideología, al contrario, aun en las prácticas que parecieran más "neutras" subyace una carga ideológica que determina no sólo el producto sino también el proceso de traducción. De nuevo, la riqueza de enfoques a la que nos remite va desde los etnográficos, revisiones históricas, análisis y comparación de versiones de un mismo texto en lenguas o momentos diferentes, hasta reflexiones sobre procesos áulicos donde, a partir de provocadores ejercicios de bi y translenguajeo, los estudiantes comparten y construyen maneras de entenderse y hacerse entender, de hacer visible al otro y asumirse como parte del otro.

Un brevísimo recorrido por los temas que se exploran incluye la autotraducción, las denominaciones de la Virgen María, las cadenas de traducción entre autores lite- 
rarios de países tan lejanos y a la vez cercanos como México y Polonia (recordemos que Pitol tradujo a Gombowicz y que José Emilio Pacheco se acercó a Miłosz); la traducción teatral con sus diversos niveles discursivos, los cantos nahuas en sus versiones nacionalista-indigenista o poético-lírica; la recepción literaria, los acercamientos antropológicos a las traducciones o versiones de documentos sobre viajes a la Isla de Pascua; los procesos de enseñanza/aprendizaje en el aula de traducción, un acercamiento a John Milton y una interesantísima defensa de la ginealogía feminista. Otros temas presentes son el de la traducción del code-switching en la literatura fronteriza, la traducción de documentos oficiales, el lugar de la literatura polaca sobre la Segunda Guerra Mundial en España y los procesos traductorales en el aula intercultural.

Como se puede observar, dentro de la riqueza que nos ofrece esta diversidad hay puntos de contacto, zonas de coincidencia, autores y corrientes que se exploran, como la propuesta de Theo Hermans o André Lefevere de la Escuela de la Manipulación, George Steiner, Gideon Toury, Basil Hatim e Ian Mason, Gayatri Spivak, Daniel Simeoni, Maria Tymoczko, Sherry Simon, Lawrence Venuti o Itamar Even-Zohar y la teoría de los polisistemas. Igualmente, el lector podrá coincidir o disentir con otros autores que, desde disciplinas afines y coincidentes, son discutidos y citados con el fin de acercar conceptos necesarios para visibilizar las cargas ideológicas en las prácticas traductoras, como pueden ser Teun A. van Dijk, Louis Althusser, Walter Mignolo u Octavio Paz. De este modo, nos acercamos a epistemologías, posturas éticas y estéticas, aspectos que interesan a los autores de los capítulos que tanto académicos como estudiantes podrán retomar, explorar y discutir tanto en clase como en sus trabajos de investigación.

Aunque al principio parece un compendio de temas algo dispares, a la vez esa característica puede apreciarse y usarse para sorpresa de quien decida leerlo en su totalidad: ¿Quién de ustedes no se sorprendería de ver a una mujer mayor cargando "piltrafas de carne"? ¿Qué significa eso en un lugar y otro? ¿Qué implica traducir de lenguas medievales a lenguas modernas? ¿Cómo se revitalizan y difunden las tradiciones? ¿Qué pasa cuando se quiere hacer pasar la práctica de la interpretación o traducción por algo inocente u objetivo? Reconocer que hay posiciones ideológicas en las que estamos insertos, que desde la subalternidad es más difícil que se escuchen ciertas voces también es un tema que aparece en varios capítulos. Aprender a usar estos y otros conceptos o dejarse seducir por nuevas ideas que provengan de lugares o disciplinas adyacentes a la traducción e interpretación es, sin duda, una fortaleza de este libro. 
Desde la investigación educativa se han trabajado temas de traducción que precisamente están en estrecha relación con las ideologías, con el poder, con el cuestionamiento de las reglas establecidas por grupos que no siempre conocen la complejidad de los procesos traductivos. Con este libro queda claro que la traducción puede ser una herramienta o un medio para llegar a comprender a la otra persona, a la otra comunidad, a la otredad ¿Entender y comprender o acercarse solamente? Nos puede permitir ¿viajar en el tiempo? ¿Entrar a otras ideologías? ¿Proponer otras formas de sentir, ver, hacer, ser? La apuesta es que a través de libros como este se abran caminos o rutas, senderos que ofrezcan ejemplos de cómo abordar el análisis o estudio de prácticas educativas, de obras literarias, de documentos históricos o de fenómenos sociales. 